\title{
Application of 1-Methylcyclopropene in Fresh-cut/Minimal Processing Systems
}

\author{
Peter M.A. Toivonen ${ }^{1}$ \\ Agriculture and Agri-Food Canada, Pacific Agri-Food Research Centre, Box 5000, 4200 Highway 97, \\ Summerland, British Columbia, Canada VOH $1 Z 0$
}

Additional index words. 1-methylcyclopropene, fresh-cut fruits, fresh-cut vegetables, shelf life, quality

\begin{abstract}
The application of 1-methylcyclopropene (1-MCP) in fresh-cut processing systems has been approached in three ways: 1) treatment of freshly harvested crop before longer-term storage after which the product is processed, 2) treatment of whole product just before processing, or 3) treatment of fresh-cut product immediately after processing. Results in the literature to date are quite variable in terms of whether 1-MCP treatment provides a benefit, no effect, or a negative effect on shelf life and quality retention of fresh-cut product. There are a number factors that impact the nature and extent of response to 1-MCP by fresh product and these include, but are not limited to, temperature of storage for fresh-cut product, condition of raw product, type of fruit or vegetable, cultivar, harvest maturity, duration of storage before cutting, and the 1-MCP treatment approach. A critical analysis, using existing published and unpublished data, provides a preliminary assessment of the impact of some of these factors. This analysis is intended to provide some insight into important considerations on the use of 1-MCP in fresh-cut processing systems and will guide researchers in considering experimental parameters for future work.
\end{abstract}

The potential impact of 1-methylcyclopropene (1-MCP) in fresh-cut fruits and vegetables has been documented only in the last several years. This article explores what is now known about 1-MCP and its effect on quality in fresh-cut products in the hopes that new research can help to fill the gaps in understanding. Before going into the discussion, it is important to note that the focus of the discussion will be on measured quality differences. However, the discussion of quality is limited by the fact that measures of soluble solids and titratable acidity were sporadically reported and, in most cases, changes in these measures were not consistent between studies. Part of the reason for the inconsistency may be explained by the discussion of CalderonLopez et al. (2005) who suggested that many quality parameters such as soluble solids and titratable acidity may not be closely linked with ethylene action and hence these measures would not be expected to show consistent response to $1-\mathrm{MCP}$ treatment.

On the other end of the spectrum, ethylene production and respiration are expected to be directly linked to 1-MCP application and they were generally reported to be affected. However, because ethylene production and respiration are not quality measures, they are not discussed in this article. However, it should be noted that 1-MCP generally has been effective at reducing both in most freshcut fruit products (Calderon-Lopez et al., 2005; Colelli and Amodio, 2003; Ergun et al., 2006; Jiang and Joyce, 2002; Mao et al., 2006; Perera et al., 2003; Rupasinghe et al., 2005). In contrast, 1-MCP treatment appears to enhance ethylene production in banana (Musa acuminata Colla) and some leafy fresh-cut vegetables (Ella et al., 2003; Jiang et al., 2002; Vilas-Boas and Kader, 2006).

It is this lack of consistency that continues to be a challenge in understanding the mode

\footnotetext{
${ }^{1}$ To whom correspondence should be addressed; e-mail toivonenp@agr.gc.ca
}

of action for 1-MCP in a wide range of freshcut fruit and vegetable products. The consistencies and inconsistencies in 1-MCP effect on quality are therefore discussed, providing some explanations in those cases in which some clues exist.

\section{FRESH-CUT CLIMACTERIC FRUIT}

1-MCP has been thus far most widely applied in whole fruits that are climacteric in their ripening behavior (Blankenship and Dole, 2003). As a consequence, the impact on fresh-cut climacteric fruit is considered separately. A wide variety of fresh-cut climacteric fruit have been studied, including apples (Malus $\times$ domestica Borkh.), tomatoes (Lycopersicon esculentum L.), kiwifruit [Actinidia deliciosa (A. Chev.) C.F. Liang et A.R. Ferguson, Actinidiaceae], papaya (Carica papaya L.), and mangoes (Mangifera indica L.). The most studied of this list are apples.

Apples. Fresh-cut apples have been studied in the context of all three application approaches listed previously [i.e., treatment of freshly harvested crop before longer-term storage after which the product is processed (TSP); treatment of whole product just before processing (TP); or treatment of fresh-cut product immediately after processing (PT)]. Each of these are discussed separately.

Five studies have been devoted to application of 1-MCP before storage, after which the fruit were removed, cut, and packaged (TSP; Bai et al., 2004; Jayanty et al., 2003; Perera et al., 2003; Rupasinghe et al., 2005). In those five studies, eight different cultivars were tested ['Empire', 'Crispin' (also called 'Mutsu'), 'Delicious', 'Idared', 'Law Rome', 'Jonagold', 'Gala', and 'Braeburn']. The maturity of the apples at harvest were reported using starch index values ('Empire', 'Crispin', 'Delicious', 'Idared', 'Law Rome') or internal ethylene concentrations ('Empire', 'Crispin', 'Delicious', 'Idared', 'Law Rome', 'Jonagold', 'Gala') or not reported at all ('Braeburn'). In addition to this variation in maturity reporting, these studies were con- ducted with varying storage durations, in air storage ('Empire', 'Crispin', 'Delicious', 'Idared', 'Law Rome', 'Gala', 'Braeburn') or air or controlled atmosphere (CA) storage ('Empire', 'Crispin', 'Jonagold'). Three of the four studies used antibrowning dips containing calcium salts, ascorbate plus other components, whereas one used only ascorbic acid (Perera et al., 2003). Those studies using the calcium ascorbate dips also held the slices at 2 to $5.5{ }^{\circ} \mathrm{C}$, whereas Perera et al. (2003) stored the cut slices at $0{ }^{\circ} \mathrm{C}$. As a consequence, it is not surprising that very few consistent results are reported among these five studies. Firmness improved with 1-MCP application for 'Delicious', 'Empire', 'Jonagold', 'Braeburn', and 'Gala' (Bai et al., 2004; Calderon-Lopez et al., 2005; Jayanty et al., 2003; Perera et al., 2003), whereas there was not a consistent improvement in firmness for 'Empire', 'Crispin', 'Idared', and 'Law Rome' (Calderon-Lopez et al., 2005; Rupasinghe et al., 2005). In regard to browning, results have been highly variable, so much so that in one study (Jayanty et al., 2003), lightness was reduced when apples were stored for 3 months before cutting, yet those held for longer terms before slicing showed better retention of lightness with 1-MCP treatment as compared against a nontreated control. 'Braeburn' and 'Gala' slices from apples treated with 1-MCP and stored 3 and 1 months, respectively, showed a marked improvement in lightness retention (Bai et al., 2004; Perera et al., 2003). In contrast to these results, the work with 'Empire', 'Crispin', 'Delicious', 'Idared', and 'Law Rome' showed no significant response in regard to slice browning with 1-MCP treatment (Calderon-Lopez et al., 2005; Rupasinghe et al., 2005). Decay was increased with 1-MCP treatment for the three studies, which used a holding temperature ranging from 4 to $5.5^{\circ} \mathrm{C}$, whereas there was no decay increase reported when slices were held at 0 to $2{ }^{\circ} \mathrm{C}$. This last observation is not unexpected, because lowering of temperature significantly delays the onset of growth of all 
microorganisms on apple slices (Toivonen et al., 2001; unpublished data).

The approach in which apples are treated before cutting (TP) is reported in two studies using 'Gala' (Bai et al., 2004) and 'Pacific Rose' (Perera et al., 2003) apples. In the case of 'Gala', the fruit were treated and cut within days of harvest, whereas in the case of 'Pacific Rose', the apples were air-stored for 3 months before treatment and cutting. The 'Gala' were harvested at a pre- or early climacteric stage as indicated by low internal ethylene concentrations; however, the maturity of the 'Pacific Rose' apples at harvest was not reported. 'Pacific Rose' was treated with a very low 1 -MCP concentration $(0.05$ $\mu \mathrm{L} \cdot \mathrm{L}^{-1}$; Perera et al., 2003), whereas 'Gala' was treated with 0.625 to $1 \mu \mathrm{L} \cdot \mathrm{L}^{-1} 1-\mathrm{MCP}$ (Bai et al., 2004). The two studies used a very different postcutting dip. In the first, 'Gala' slices were treated with a dip containing calcium ascorbate, calcium propionate, and acetylcysteine, whereas in the second, 'Pacific Rose' slices were treated with ascorbic acid. Postcutting holding temperatures were also very different: 'Pacific Rose' was held at $0{ }^{\circ} \mathrm{C}$, whereas 'Gala' was held at 5.5 ${ }^{\circ} \mathrm{C}$. These two studies gave totally contrasting results, which is not surprising considering the great differences in cultivars, storage, and treatment protocols. Firmness and acidity retention were consistently improved in the 'Gala' apples held at $5.5^{\circ} \mathrm{C}$, whereas lightness was only improved in the 'Pacific Rose' slices held at $0{ }^{\circ} \mathrm{C}$. Decay was an issue in 'Gala' slices (Bai et al., 2004), but not at $0{ }^{\circ} \mathrm{C}$ for the 'Pacific Rose' slices (Perera et al., 2003).

There is only one report in the literature regarding the postcutting treatment of apples with 1-MCP (Jiang and Joyce, 2002). That study was done with 'Golden Delicious' apples acquired from the local market and there was no quantitative quality criteria reported for the fruit used in the study. No significant effects on quality were shown for apples treated after cutting with 1-MCP and held at $4{ }^{\circ} \mathrm{C}$ for $10 \mathrm{~d}$.

The collective work that has been done with apple slices suggests that many factors likely influence response to $1-\mathrm{MCP}$. However, because of lack of consistency in the experiment protocols, it is very difficult to draw firm conclusions as to whether 1-MCP use is generally beneficial. It can be stated that firmness can be improved in many instances when 1-MCP is applied at harvest, before fruit are stored or processed into fresh slices.

One issue that has clouded some of the work is the use of low temperatures for holding slices. Studies with 'Braeburn' and 'Pacific Rose' were done using $0{ }^{\circ} \mathrm{C}$ as a holding temperature after slicing (Perera et al., 2003). This is not considered a realistic temperature for fresh-cut products in general. Holding temperatures used by most of the other studies $\left(4\right.$ to $5.5^{\circ} \mathrm{C}$ ) are more typical of expected temperatures in the distribution chain for apple slices and other fresh-cut products (Toivonen et al., 2001).

Tomatoes. A single report of the impact of 1-MCP has been published for fresh-cut field tomato slices (Jeong et al., 2004b). The examined two approaches: 1) treatment of intact tomatoes with 1-MCP and slicing (TP), and 2) treatment of slices with 1-MCP (PT). Slices were held in ventilated plastic containers such that no modified atmosphere (MA) developed during the experiments. Firmness was best retained in slices treated with 1 $\mu \mathrm{L} \cdot \mathrm{L}^{-1} 1-\mathrm{MCP}$ at $5{ }^{\circ} \mathrm{C}$ for $24 \mathrm{~h}$ and stored at $5{ }^{\circ} \mathrm{C}$. No benefit was obtained with 1-MCP treatment of intact fruit before slicing. Watersoaking, a defect that develops in tomato slices (Jeong et al., 2004b), was more prevalent when tomatoes of more advanced maturity were used for slicing. 1-MCP was effective at controlling water-soaking in slices when it was applied to sliced tomatoes at the light red maturity stage. Even within that color-determined maturity stage, the firmer the fruit slices, the better the 1-MCP response in terms of firmness retention and elimination of water-soaking.

Other fruits. Vilas-Boas and Kader (2001) reported on the effect of 1-MCP treatment on fresh-cut bananas, kiwifruits, mangoes, and persimmons (Diospryros kaki L.f.). Banana did not respond when whole fruit were treated before cutting (TP), but a postcutting application reduced softening of slices (PT; VilasBoas and Kader, 2001, 2006). Kiwifruit fruit responded positively to $1-\mathrm{MCP}$ with reduced softening when either whole fruit or slices were treated (TP and PT). This result was also found by Colelli and Amodio (2003) for kiwifruit. Mango response was similar to that of banana, only showing reduced softening when cubes were treated (Vilas-Boas and Kader, 2001). In persimmons, treating whole fruit before cutting (TP) was the most effective approach to reduce softening of wedges. In no case did $1-\mathrm{MCP}$ treatment reduce discoloration in fresh-cut product.

Jeong et al. (2004a) found that the treatment of entire muskmelon (Cucumis melo L.) immediately before cutting had no effect on firmness or quality retention of cubes. The fruits used in this study were three-fourths to full-slip stages of maturity. Cubes of untreated control and 1-MCP-treated fruit showed very little softening after $12 \mathrm{~d}$ at $5{ }^{\circ} \mathrm{C}$. No effect was seen on flesh color or soluble solids content of the cubes, but increased decay was found in the cubes made from 1-MCP-treated fruit.

Ergun et al. (2006) found that 1-MCPtreated intact papaya (TP) resulted in improved firmness retention in slices. This effect was retained, even if fruit were held up to $10 \mathrm{~d}$ at $5{ }^{\circ} \mathrm{C}$ before slicing. The most significant effect of 1-MCP treatment was increased firmness retention, but color retention was also improved at the latter part of the 10-d storage of slices.

\section{NONCLIMACTERIC FRUITS AND VEGETABLES}

Pineapples. Budu and Joyce (2003) examined the use of 1-MCP for fresh-cut pineapple (Ananas comosus L. Merr.). They treated the fruit the day before processing
(TP). In initial studies, the maximal benefit from 1-MCP was achieved with a dose of $1 \mu \mathrm{L} \cdot \mathrm{L}^{-1}$ for $18 \mathrm{~h}$ at $20^{\circ} \mathrm{C}$. In that study, the authors compared response to 1-MCP with or without a postcutting dip of $2 \%$ ascorbic acid for $3 \mathrm{~min}$. The cut pineapple semicircular slices were held in glass jars covered with microperforated film at $4.5^{\circ} \mathrm{C}$ for up to $12 \mathrm{~d}$. According to the authors' recollection, the shelf life could be doubled from 4 to $8 \mathrm{~d}$ using 1-MCP treatment and that was probably the result of the effects seen in the visual quality rating. However, 1-MCP only improved L and $\mathrm{b}$ color value retention when the ascorbic acid dip was not used. In addition, 1-MCP had no significant effect on firmness retention. Overall, on reviewing the results, it appears that a $2 \%$ ascorbic acid dip had a far more significant effect on quality retention than 1-MCP for fresh-cut pineapples.

Strawberries. Aguayo et al. (2006) found that application of 1-MCP before or after cutting strawberries (Fragaria ×ananassa Duchesne) into wedges had no significant effect on improving visual quality or firmness retention at $5{ }^{\circ} \mathrm{C}$, although the treatment reduced ethylene production. However, when a $1-\mu \mathrm{L} \cdot \mathrm{L}^{-1} 1-\mathrm{MCP}$ treatment was applied for $24 \mathrm{~h}$ at $5{ }^{\circ} \mathrm{C}$ (before or after cutting) and followed by a postcutting dip of $1 \% \mathrm{CaCl}_{2}$ and a CA of $10 \mathrm{kPa} \mathrm{CO}_{2}+3 \mathrm{kPa} \mathrm{O}_{2}$ then applied, the fruit quality retention was significantly improved. The authors indicated that the high $\mathrm{CO}_{2}$ atmosphere was important in controlling mold growth, and this was particularly important because mold growth has been enhanced in fruit treated with 1MCP (Aguayo et al., 2006). The mechanism for this enhancement of mold growth has been suggested because that 1-MCP may block perception of wound ethylene, which is important in disease resistance ( $\mathrm{Ku}$ et al., 1999).

Leafy vegetables. The use of 1-MCP on fresh-cut leafy vegetables has been extensively studied. Although it appears that 1MCP can halt ethylene-induced metabolism such as the phenylpropanoid pathway, the same does not appear to be true for controlling wounding-induced increase in phenolic compounds accumulation (Saltveit, 2004). Therefore, it follows that much of the successful responses to 1-MCP in leafy vegetables relate to mitigation of response to exogenous ethylene (Able et al., 2002, 2003; Bron et al., 2005; Jiang et al., 2002; Koukounaras et al., 2006; $\mathrm{Ku}$ and Wills, 1999). However, there are some reports indicating that 1-MCP can be beneficial to a few leafy vegetables in the absence of an exogenous source of ethylene (Able et al., 2002, 2003; Ella et al., 2003; Tay and Perera, 2004). The level benefits obtained by using $1-\mathrm{MCP}$ in these vegetables are probably not sufficient or consistent enough to justify the costs involved (O'Hare and Wong, 2002). The conclusion that can be drawn from this body of work is that 1-MCP applications could be useful in situations in which raw product is handled alongside ethylenegenerating produce (e.g., tomatoes, bananas, 
or apples) before processing or if the cut leafy products are packaged with ethylene-generating products as part of a specialty mix.

\section{COMBINED TREATMENT APPROACH}

One area that has only been explored more recently is the use of 1-MCP as a cotreatment with treatments that control aspects of quality change other than ripening. There are a few papers demonstrating that $1-\mathrm{MCP}$, when combined with other postcutting treatments, has a synergistic effect on quality retention and control of decay (Aguayo et al., 2006; Luo, 2005; Mao et al., 2006; Toivonen and $\mathrm{Lu}$, 2006). It has to be kept in mind that the mechanism of action for 1-MCP is to block ethylene perception and hence it can only be relied on to inhibit ripening and ethyleneinduced senescence. There are several reports indicating that 1-MCP treatment can lead to increased decay or microbial growth in freshcut fruits and vegetables (Bai et al., 2004; Budu and Joyce, 2003; Jeong et al., 2004a). In other cases, there are no significant effects on microbial growth (Aguayo et al., 2006; Rupasinghe et al., 2005). Yet, for fresh-cut watermelon [Citrullus lanatus (Thunb.) Matsum. and Nakai] in which ethylene exposure has been shown to enhance microbial growth, 1-MCP treatment has been reported to reduce microbial growth (Zhou et al., 2006). The scatter of results in relation to just 1-MCP application in various fresh-cut fruits and vegetable suggests that factors other than 1-MCP alone are responsible for determining microbial growth and decay on fresh-cut products. $\mathrm{Ku}$ et al. (1999) suggested that 1-MCP knocked out the ethylene-associated wound response important to disease resistance mechanisms. Hence, it may be that in product-microbe combinations in which the disease resistance is a factor, 1MCP may enhance decay. However, for cases in which microorganisms do not elicit wound ethylene response and there is no exogenous ethylene source, 1-MCP application may have no effect on their growth on cut surfaces of fruits or vegetables. In the third case, in which ethylene-sensitive product is exposed to ethylene in mixed storage before processing or in packaged mixes, 1-MCP may be beneficial in controlling senescence-associated decay and microbial growth.

A few reports have shown that combining 1-MCP with other postcutting treatments and MAs can lead to synergistic effects on both sensory and microbiological quality of freshcut fruits. Aguayo et al. (2006) found that combining a $1-\mu \mathrm{L} \cdot \mathrm{L}^{-1} 1-\mathrm{MCP}$ treatment $(24 \mathrm{~h}$ at $5{ }^{\circ} \mathrm{C}$ before cutting), a $1 \% \mathrm{CaCl}_{2}$ dip (for $2 \mathrm{~min})$, and a MA ( $\left.3 \mathrm{kPa} \mathrm{O}_{2}+10 \mathrm{kPa} \mathrm{CO}_{2}\right)$ provided a synergistic benefit in terms of reduced softening and visual appearance retention. Mao et al. (2006) found that a combination of $1-\mathrm{MCP}\left(10 \mu \mathrm{L} \cdot \mathrm{L}^{-1}\right)$ plus calcium dip $\left(2 \% \mathrm{CaCl}_{2}\right)$ was synergistic in reducing aerobic bacterial growth in freshcut watermelon. However, firmness was best retained in a single postcutting calcium dip without 1-MCP pretreatment.
Luo (2005) reported that combining 1MCP treatment on intact carrots (Daucus carota L.), cilantro (Coriandrum sativum L.), and apples before cutting, combined with a postcut sanitation with acidified sodium chlorite, results in good control of quality, decay, and microbial growth. On review of the data for cilantro (Kim, Tao, and Luo, 2006, unpublished data), it is not clear whether this synergistic effect large enough to justify the added treatment cost with 1MCP, because the largest portion of the benefit is directly attributable to the acidified sodium chlorite alone.

Recently, a combined 1-MCP-based technology was designed to deal with the control of quality loss and microbial growth (Toivonen and $\mathrm{Lu}, 2006$ ). The technology involves the blending of SmartFresh (i.e., immobilized 1MCP) with various simple carbohydrates and dehydrated yeasts in a sachet or tablet form. When this sachet is sealed within a properly selected film (one that ensures high carbon dioxide atmospheres), the yeast becomes activated by the humidity generated by the freshcut product in the package. Once activated, the yeast metabolizes both the cyclodextrin skeletons that immobilize the 1-MCP (i.e., SmartFresh) and the other carbohydrates in the mixture. Carbon dioxide (in excess of that produced by the fresh-cut fruit or vegetable), ethanol and acetaldehyde are then cogenerated with the release of the 1-MCP molecule from the cyclodextrin. Consequently, both the freshcut product physiology and microbial growth are impacted simultaneously.

An example of the results obtained using this new technology for fresh apple slices is
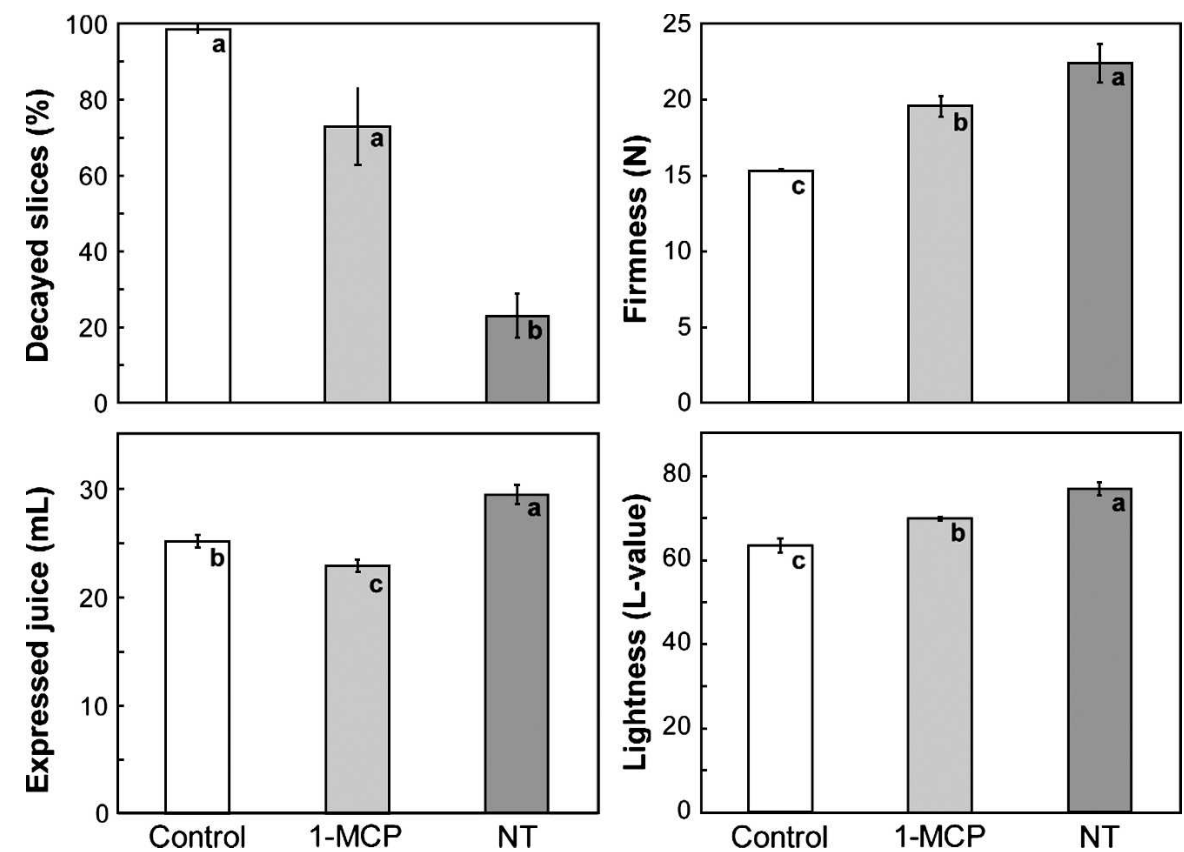

Fig. 1. Differences in quality for 'Gala' apple slices after 8 weeks storage at $3{ }^{\circ} \mathrm{C}$. Slices were dipped in Nature Seal (Mantrose-Haeuser Co., Westport, CT) before packaging and left untreated (control), $1 \mu \mathrm{L} \cdot \mathrm{L}^{-1} 1$ methylcyclopropene (1-MCP) applied in packaged (1-MCP), or a sachet of new technology sealed in the package (NT). Decay data represent the percent of slices affected, firmness determined with a Kramer shear press, expressed juice (i.e., juiciness) from a 100-g sample of slices in a Kramer shear press, and lightness determined with a Minolta chromameter. Note: $\mathrm{n}=4$ and bars marked with a different letter within a graph frame are significantly different according to a least significant difference $(P<0.05)$ test. 


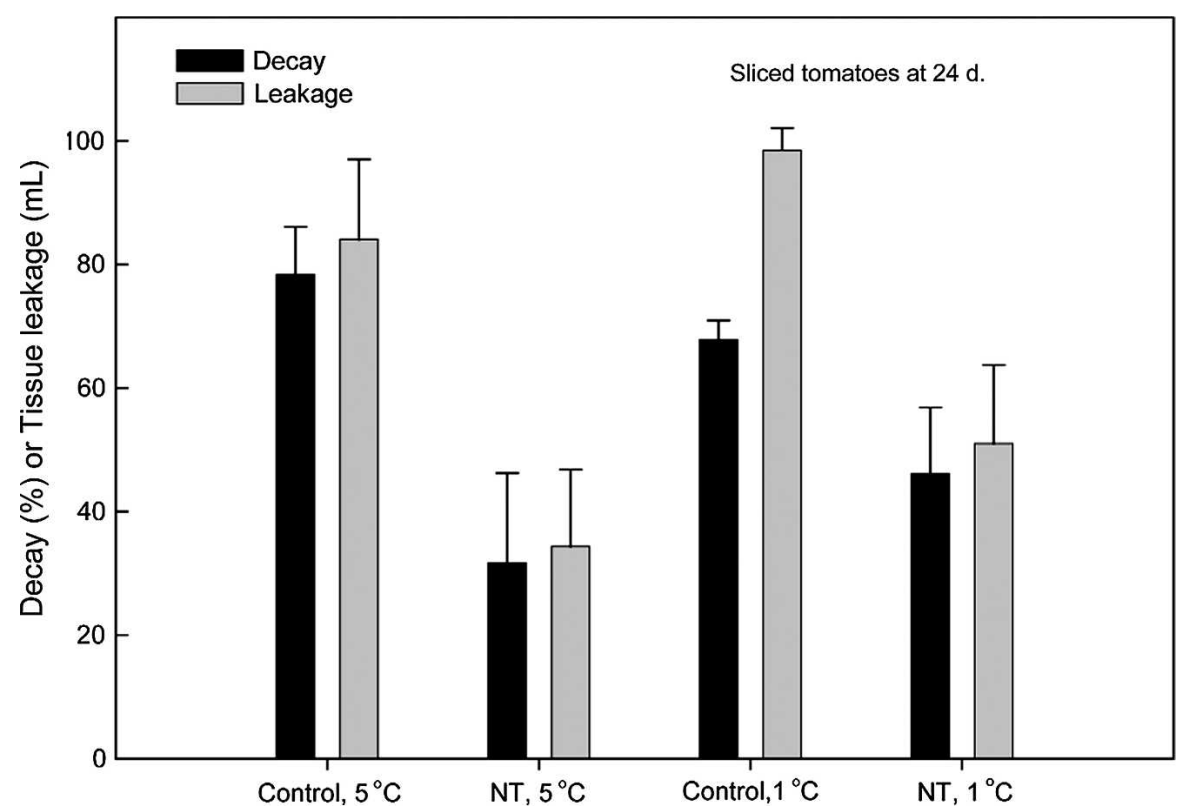

Fig. 2. Reduction of decay and tissue leakage for greenhouse beefsteak tomato slices packaged in Fresh-RPax tomato trays (Maxwell Chase Technologies, LLC, Atlanta, GA) with new technology (NT) sachets as compared with control tomato trays. The packages were held at two different storage temperatures. Error bars represent SE of the means.

treatments or appropriate atmospheres to achieve treatment response synergies leading to consistent quality (sensory and microbial) and shelf life improvement. At this time, the application of postcutting dips containing calcium and perhaps ascorbate is an essential requirement for fresh-cut fruit and $1-\mathrm{MCP}$ seems to add to the benefit obtained with such dips. High carbon dioxide atmospheres also appear to be highly beneficial and provide better and more consistent responses when combined with 1-MCP. Unfortunately, very few of the papers in the 1-MCP literature have explored this approach. More recently, a corelease technology has been developed, and this provides a microbial/quality combination that provides high carbon dioxide, antimicrobial volatiles, and 1-MCP. The commercial feasibility of this technology is yet to be tested, but the concept of multifunctional approaches, including 1-MCP, to quality and safety management will probably provide the fresh-cut industry with the greatest potential gains in the future.

\section{Literature Cited}

Able, A.J., L.S. Wong, A. Prasad, and T.J. O'Hare. 2002. 1-MCP is more effective on a floral brassica (Brassica oleracea var. italica L.) than a leafy brassica (Brassica napa var. chinensis). Postharvest Biol. Technol. 26:147-155.

Able, A.J., L.S. Wong, A. Prasad, and T.J. O'Hare. 2003. The effects of 1-methylcyclopropene on the shelf life of minimally processed leafy Asian vegetables. Postharvest Biol. Technol. 27:157-161.

Aguayo, E., R. Jansasithorn, and A.A. Kader. 2006. Combined effects of 1-methylcyclopropene, calcium chloride dip, and/or atmospheric modification on quality changes in fresh-cut strawberries. Postharvest Biol. Technol. 40:269-278.

Bai, J., E.A. Baldwin, R.C. Soliva-Fortuny, J.P. Mattheis, R. Stanley, C. Perera, and J.K.
Jeong, J., J. Brecht, D. Huber, and S. Sargent. 2004b. 1-Methylcyclopropene (1-MCP) for maintaining texture quality of fresh-cut tomato. HortScience 39:1359-1362.

Jiang, Y. and D.C. Joyce. 2002. 1-Methylcyclopropene treatment effects on intact and freshcut apple. J. Hort. Sci. Biotechnol. 77:19-21.

Jiang, W., Q. Sheng, X.-J. Zhou, M.-J. Zhang, and X.-J. Liu. 2002. Regulation of detached coriander leaf senescence by 1-methylcyclopropene and ethylene. Postharvest Biol. Technol. 26:339-345.

Koukounaras, A., A.S. Siomos, and E. Sfakiotakis 2006. 1-methylcyclopropene prevents ethylene induced yellowing of rocket leaves. Postharvest Biol. Technol. 41:109-111.

$\mathrm{Ku}$, V.V.V. and R.B.H. Wills. 1999. Effect of 1methylcyclopropene on the storage life of broccoli. Postharvest Biol. Technol. 17:127-132.

Ku, V.V.V., R.B.H. Wills, and S. Ben-Yehoshua. 1999. 1-Methylcyclopropene can differentially affect the postharvest life of strawberries exposed to ethylene. HortScience 34:119-120.

Luo, Y. 2005. Emerging technologies for improving food safety and quality of fresh-cut produceAcidified sodium chlorite and 1-methylcyclopropeneInstitute of Food Technologists meeting abstracts 2005. 17 May 2006. <http://ift.confex. com/ift/2005/techprogram/paper_27839.htm>.

Mao, L., J. Jeong, F. Que, and D.J. Huber. 2006. Physiological properties of fresh-cut watermelon (Citrullus lanatus) in response to 1methylcyclopropene and post-processing calcium application. J. Sci. Food Agr. 86:46-53.

Brecht. 2004. Effect of pretreatment of intac 'Gala' apple with ethanol vapor, heat, or 1methylcyclopropene on quality and shelf lie of fresh-cut slices. J. Amer. Soc. Hort. Sci. 129:583-593.

Blankenship, S.M. and J.M. Dole. 2003. 1-Methylcyclopropene: A review. Postharvest Biol. Technol. 28:1-25.

Bron, I.U., D.C.C. Vitti, R.A. Kluge, M.C. de Arruda, A.P. Jacomino, and G.P.P. Lima. 2005. Influence of low temperature storage and 1-methylcyclopropene on the conservation of fresh-cut watercress. Brazilian J. Food Technol. 8:121-126.

Budu, A.S. and D.C. Joyce. 2003. Effect of 1methylcyclopropene on the quality of minimally processed pineapple fruit. Austr. J. Expt. Agr. 43:177-184.

Calderon-Lopez, B., J.A. Bartsch, C.Y. Lee, and C.B. Watkins. 2005. Cultivar effects on quality of fresh-cut apple slices from 1-methylcyclopropene (1-MCP)-treated apple fruit. J. Food Sci. 70:S221-S227.

Colelli, G. and M.L. Amodio. 2003. Effetti del trattamento con 1-MCP di frutti di actinidia interi e a fette (Effects of 1-MCP treatments on whole and fresh-cut kiwifruits). Rivista di Frutticoltura e di Ortofloricoltura 65:61-67.

Ella, L., A. Zion, A. Nehemia, and L. Amnon. 2003. Effect of the ethylene action inhibitor 1methylcyclopropene on parsley leaf senescence and ethylene biosynthesis. Postharvest Biol. Technol. 30:67-74.

Ergun, M., D.J. Huber, J. Jeong, and J.A. Bartz. 2006. Extended shelf life and quality of freshcut papaya derived from ripe fruit treated with the ethylene antagonist 1-methylcyclopropene. J. Amer. Soc. Hort. Sci. 131:97-103.

Jayanty, S., K. Tanprasert, B. Harte, and R. Beaudry. 2003. Apple storage connection to fresh-cut. Fresh-cut apple slices: Research to reality, 26 June 2003. Michigan State University Extension.

Jeong, J., J. Brecht, D. Huber, and S. Sargent. 2004a. Influence of 1-methylcyclopropene on the shelf life and deterioration of fresh-cut cantaloupe. HortScience 39:816.
O'Hare, T.J. and L.S. Wong. 2002. Leafy Asian vegetables. Extending their shelf life: Part 2. Rural Industries Research Development Corporation Publication No. 02/006.

Perera, C.O., L. Balchin, E. Baldwin, R. Stanley, and M. Tian. 2003. Effect of 1-methylcyclopropene on the quality of fresh-cut apple slices. J. Food Sci. 68:1910-1914

Rupasinghe, H.P.V., D.P. Murr, J.R. DeEll, and J. Odumeru. 2005. Influence of 1-methylcyclopropene and NatureSeal on the quality of fresh-cut 'Empire' and 'Crispin' apples. J. Food Qual. 28:289-307.

Saltveit, M.E. 2004. Effect of 1-methylcyclopropene on phenylpropanoid metabolism, the accumulation of phenolic compounds, and browning of whole and fresh-cut 'iceberg' lettuce. Postharvest Biol. Technol. 34:75-80.

Tay, S.L. and C.O. Perera. 2004. Effect of 1methylcyclopropene treatment and edible coatings on the quality of minimally processed lettuce. J. Food Sci. 69:C131-C135.

Toivonen, P.M.A., P. Delaquis, M. Cliff, T. Beveridge, and L. Moyls. 2001. Development of apple quality standards for slicing and optimization of sanitation procedures, p. 112-117. Washington Tree Fruit Research Commission, Apple Postharvest Research Review, July 26, 2001Wenatchee, WA.

Toivonen, P.M.A. and C. Lu. 2006. Compositions and methods to improve the storage quality of packaged plants. U.S. Patent Application 20060154822, 13 July 2006.

Vilas-Boas, E.V.de B. and A.A. Kader. 2001. Effect of 1-MCP on fresh-cut fruits. Perishables Handling Quarterly 108:25.

Vilas-Boas, E.V.de B. and A.A. Kader. 2006. Effect of atmospheric modification, 1-MCP and chemicals on the quality of fresh-cut banana. Postharvest Biol. Technol. 39:155-162.

Zhou, B., J.L. McEvoy, Y. Luo, R.A. Saftner, H. Feng, and T. Beltran. 2006. 1-Methylcyclopropene counteracts ethylene-induced microbial growth on fresh-cut watermelon. J. Food Sci. 71:M180-M184. 